\title{
Urdimento
}

Revista de Estudos em Artes Cênicas E-ISSN: 2358.6958

\section{Summer and Smoke, de Tennessee Williams, no Brasil: Título alterado, melodrama e acting edition}

\author{
Luis Marcio Arnaut de Toledo
}

\section{Para citar este artigo:}

TOLEDO, Luis Marcio de. Summer and Smoke, de Tennessee Williams, no Brasil: Título alterado, melodrama e acting edition. Urdimento, Florianópolis, v. 1, n. 40, mar./abr. 2021.

d. DOI: http:/dx.doi.org/10.5965/1414573101402021e0203 
Summer and Smoke, de Tennessee Williams, no Brasil: Título alterado, melodrama e acting edition

Luis Marcio Arnaut de Toledo ${ }^{1}$

\begin{abstract}
Resumo
Este trabalho fez uma descrição de forma e conteúdo de Summer and Smoke, de Tennessee Williams, com uma análise de sua contextualização histórico-social. Além disso, apresentou sua recepção e encenações principais. Indicou e comentou criticamente aspectos da tradução publicada no Brasil, de uma versão diferente daquela que o autor desejava. Esta, por sua vez, contribuiu para uma leitura hegemônica da obra de Williams no país. Foi apresentada, também, uma leitura comparativa da segunda versão da peça, jamais publicada ou levada aos palcos brasileiros. Por fim, discutiu os aspectos que possivelmente levaram à mudança do título em português.
\end{abstract}

Palavras-chave: Dramaturgia. Teatro. Artes Cênicas. Tennessee Williams.

\title{
Tennessee Williams' Summer and Smoke in Brazil: Title changed, melodrama and acting edition
}

\begin{abstract}
This work described the form and content of Tennessee Williams' Summer and Smoke, with a critical analysis of its historical, cultural and biographical context, as well as a brief notion of its reception and main performances on Broadway and in Brazil. In addition, indicated and critically commented on aspects of the Brazilian translation published, a version that contributed to an unfocused reading of the original text, without being committed to the same dramaturgical elements of Williams, including the change of the original title. Finally, a comparative reading of the second version was presented, never published or performed in Brazilian stages.
\end{abstract}

Keywords: Dramaturgy. Theater. Performing Arts. Tennessee Williams.

\footnotetext{
Doutor em Artes pela Escola de Comunicação e Artes (ECA -USP) em Teoria e Prática do Teatro. Especialista em Teatro-Educação. Licenciado em Teatro. Engenheiro e Mestre em engenharia. Dramaturgista, tradutor e revisor de Not about Nightingales para a Cia Triptal em 2019 para o espetáculo Inferno - um interlúdio expressionistacom direção de André Garolli. Convidado especial do Provincetown Tennessee Williams Theater Festival na cidade de Provicetown, nos Estados Unidos, para apresentar o panorama da obra de Tennessee Williams no Brasil em 2019 e representar o Brasil no Festival. Autor do livro Tennessee Williams: Algo não dito, 2017, editora Giostri. Com mais cinco livros publicados, é ator, educador e dramaturgo. sp.vi@hotmail.com

(9) http://lattes.cnpq.br/4787318119909108 (iD https://orcid.org/0000-0002-9301-2339
} 
Summer and Smoke, de Tennessee Williams, en Brasil: Título modificado, melodrama y acting edition

\section{Resumen}

Este trabajo describió la forma y contenido de Summer and Smoke, de Tennessee Williams, con un análisis de su contexto histórico-social. Además, presentó su recepción y escenarios principales. Indicó críticamente y comentó aspectos de la traducción publicada en Brasil, en una versión diferente a la que quería el autor. Esto, a su vez, contribuyó a una lectura hegemónica del trabajo de Williams en el país. También se presentó una lectura comparativa de la segunda versión de la obra, nunca publicada ni llevada a escenarios brasileños. Finalmente, habló de los aspectos que posiblemente llevaron al cambio de título en portugués.

Palabras clave: Dramaturgia. Teatro. Artes Escénicas. Tennessee Williams. 


\section{Summer and Smoke: uma peça pouco celebrada}

A peça Summer and Smoke [O verão e a fumaça, em tradução literal, 1948] (Williams, 1990, p.113-256) do dramaturgo estadunidense Tennessee Williams é uma de suas obras pouco celebradas e encenadas da sua fase mais famosa. Este período muito prestigiado de sua carreira [1945-1961] é repleto de premiações e consagração no mainstream, como The Glass Menagerie [0 zoológico de vidro, 1943-44] e A Streetcar Named Desire [Um bonde chamado Desejo, 1946].

Summer... possui um caminho tanto de fracasso inicial na Broadway quanto, em certo modo, de incompreensão artística no Brasil. Isso, certamente, por ter tido raras encenações, a insistência na leitura hegemônica realista e de psicologismo e pela ausência de uma tradução publicada que reproduza a versão da peça que Williams trabalhou para o formato de livro. Assim, revela-se, no país, uma injustificada negligência em conhecer em profundidade uma obra que contribuiu historicamente para a modernização do próprio teatro brasileiro.

Esse trabalho compreende e denota esta peça como uma obra singular, assim faz uma descrição de forma e conteúdo, além de uma análise crítica de suas contextualizações histórica, social e cultural, fugindo da leitura tradicional da obra do autor. Expressa, além disso, o encadeamento biográfico com esses contextos, por meio de uma breve noção de sua recepção e encenações principais na Broadway e no Brasil. Indica e comenta criticamente aspectos da tradução publicada no país, a qual contribuiu para uma leitura desfocada do texto original.

Assim sendo, discute a mudança do título nas montagens brasileiras, fato ocorrido apenas no Brasil. Para tanto procura verificar o quanto essa versão traz contextos ideológicos que fortalecem a leitura hegemônica. Além disso, é cotejada, pela primeira vez, uma leitura crítica e comparativa da versão intitulada The Eccentricities of a Nightingale [As excentricidades de um rouxinol, 1951-1964] (Williams, 1990, p.1-111), jamais publicada ou levada aos palcos brasileiros. 
Summer... foi encenada comercialmente pela primeira vez em 1948 na Broadway, permanecendo até janeiro do ano seguinte. Teve produção e direção de Margo Jones, que já tinha dirigido, três anos antes, a também desconhecida no Brasil, You Touched Me! [Quando você me tocou!, em tradução livre, 1942] — uma parceria de Williams com Donald Windham. Ambos os espetáculos não foram um grande sucesso de público, ao se comparar com as 885 apresentações de Um bonde..., em 1947, maior triunfo comercial do autor até hoje. Embora a primeira direção de Jones tenha tido uma boa acolhida da crítica, a segunda foi, também, pouco reconhecida, dada a parca bilheteria para a época, comparando, também, com o sucesso de o zoológico..., em 1945, que chegou à marca de 565 apresentações, um número extraordinário para um autor estreante no sistema.

Somente em 1952 uma montagem atrairia o interesse maior do público e chamaria a atenção dos jornalistas e críticos. Dirigido pelo panamenho José Quintero, o espetáculo foi responsável por legitimar, então, o circuito offBroadway, no teatro Circle in the Square. Sua arquitetura era uma inovação para a cena estadunidense até então, devido ao formato de semiarena, que dava à produção um aspecto pouco convencional aos espetáculos esperados pelos tradicionais da época, possibilitando uma visão mais ampla dos atores em cena, inclusive por diversos ângulos. Quintero apostava na ex-modelo Geraldine Page para interpretar Alma, a personagem principal.

A adaptação fílmica aconteceu em 1961, dirigida por Peter Glenville. Trazia também Geraldine Page, muito embora não tenha sido um destaque comercial entre as diversas obras adaptadas para o cinema durante sua fase prestigiada nos Estados Unidos. No Brasil, o filme nunca foi lançado comercialmente em VHS ou DVD, apesar de uma distribuição discreta nos cinemas na primeira metade daquela década.

Entre os anos de 1950 e 1968, momento em que várias peças suas foram adaptadas por Hollywood, esta foi uma que ajudou a popularização e a glamourização de sua obra no mundo todo, mesmo não sendo considerada comercialmente viável, como várias outras que foram adaptadas na mesma 
década de 1960. O filme é tido por Palmer e Bray (2009, p. 211, 215) como um oportuno e fiel retrato da decadência do Sul dos Estados Unidos, embora de forma exótica e deslocada da realidade, pois retrata a região com os mesmos estereótipos do filme E o vento levou... [Gone with the Wind..., 1939, direção de Victor Fleming].

A peça voltou à Broadway 48 anos após a primeira produção, em 1996, com direção de David Warren, ainda com desinteresse do público e da crítica. Ao se observar que dos 58 espetáculos de Williams, neste circuito nova-iorquino, Summer... teve apenas duas montagens até 2021, não é difícil perceber que foi encarada com desapreço e, dessa forma, evidencia-se seu pouco vigor comercial.

Em 2018, uma jovem diretora inglesa, Rebecca Frecknall, fez uma reformulação completa da encenação da obra. Evitando o realismo, ela ousou com expedientes expressionistas, como contemporaneamente a obra de Williams tem sido lida. O espetáculo teve a participação de Patsy Ferran, atriz britânica que vem chamando atenção nos palcos de Londres com sua atuação sempre elogiada (Billington, 2018).

Assim como a peça Um bonde..., Summer... teve uma pouco conhecida versão para ópera, escrita em 1971, com libreto do insigne dramaturgo Langford Wilson e com música de Lee Hoiby. Foi levada aos palcos pela primeira vez, em dezembro de 2010, pelo Manhattan School of Music e, em 2018, pelo Converse College. Ambas, também, não tiveram aclamação popular.

A peça é uma adaptação de seu próprio conto O pássaro amarelo [The Yellow Bird, escrito entre 1941 e 1947] (Williams, 2006, p. 281-289; 1994, p. 174179), publicado pela primeira vez em 1948. A ave seria uma remissão à fênix, um símbolo do modernismo britânico que Williams recuperou de referências de obras do escritor, poeta e dramaturgo inglês D. H. Lawrence, figurando o renascimento e a renovação.

Sob essa égide, Alma, filha de um ministro anglicano, vai aos poucos deixando a vida reprimida, enrustida, conservadora e religiosa para viver sua 
sexualidade em plenitude. Uma figura importante nas obras de Lawrence, a fênix é um símbolo já usado por Williams na peça em um ato / Rise in Flame Cried the Phoenix [Eu me levanto das cinzas, gritou a Fênix, 1941], além de ter, também, uma remissão em Camino Real [1953] e em Orpheus Descending [A descida de Orfeu, 1957].

A referência ao pássaro faz, portanto, uma ponte com o Egito, posto que é um mito da antiguidade egípcia o qual representa a imortalidade e os ciclos da natureza; a mitologia grega; e o modernismo britânico. Todavia, como a ave é chamada no conto de Bobo, também indica uma origem latina, tal como o próprio nome da personagem central - Alma, o princípio imaterial do ser humano, que traduz sua essência, espírito, inteligência e emoções, sendo imortal, tal como a própria ave.

A origem desses trabalhos, peça e conto, está na obra do literário inglês D. H. Lawrence, A virgem e o cigano [The Virgin and the Gypsy², 1926] (Lawrence, 1970; 2020), publicada postumamente em 1930. A novela traz Lucille e Yvette, filhas de um pastor anglicano, que tiveram uma educação pudica, muito rígida e controladora, tendo desejos sexuais suprimidos. Com a chegada de um grupo de ciganos na região, a virginal Yvette, é resgatada ao cair na enchente do rio da propriedade do pai. A despeito da intensa atração sexual entre ambos, o charmoso e másculo cigano a entrega ilesa para o pai, que supera seus preconceitos étnicos e de classe, reconhecendo o rapaz como um homem de valor moral.

Uma proximidade impressionante com diversos elementos da obra de Williams: a paixão delicada e espiritual de Alma por John Buchanan Junior em Summer...; a ausência de envolvimento sexual entre os dois; a representação da educação repressora em Alma e Yvette e a vida mundana em John e no cigano; os dois rapazes como estereótipos da masculinidade para fazer contraponto com os da feminilidade passiva; além da enchente remeter às monções que também inundam o rio Mississipi, região em que está locada a ação de Summer...

\footnotetext{
${ }^{2}$ Grafia da palavra conforme o inglês britânico do início do Século XX. A grafia atual é gipsy.
} 


\section{Summer and Smoke se torna O anjo de pedra no Brasil}

Summer... teve um reconhecido sucesso na montagem de 1950, no Teatro Brasileiro de Comédia [TBC], portanto, somente em cartaz em São Paulo e Rio de Janeiro, com direção de Luciano Sauce, estrelando Maurício Barroso e Cacilda Becker. Teve a tradução de Raimundo Magalhães Júnior, que, além desta, fez a de A rosa tatuada [The Rose Tattoo, 1950] e de Gata em telhado de zinco quente [Cat in hot tin roof, 1954], também para a importante Companhia paulistana. Infelizmente, uma tradução difícil de se encontrar cópias para se ter uma noção de como o texto em português foi tratado. Nove anos depois, houve uma nova montagem com a mesma tradução, estreando no Rio de Janeiro com Nathália Timberg, Leonardo Villar e direção de Geraldo Queirós. No ano seguinte, dirigido por Benedito Corsi, o mesmo elenco subiu aos palcos de São Paulo.

Somente em 2011, os paulistanos viram outra encenação da peça, no antigo Teatro Paulo Eiró, na sensível visão da diretora Inês Aranha. O elenco era formado por atores e atrizes afrodescendentes, uma concepção ousada em se tratando da montagem de uma obra canônica de Williams e rara no Brasil. Alves Jr. (2011) comenta, em sua crítica na revista Veja, que fora uma aposta da diretora na simplicidade para respeitar a obra pouco conhecida de Williams no Brasil.

Segundo o que se tem documentado, pela primeira vez foi utilizada a tradução de Sérgio Viotti (Williams, 1968b), que já tinha sido publicada em 1964 e reeditada em 1968, único contato dos brasileiros com este texto traduzido de Williams no mercado editorial até o momento. A edição é esgotada, porém encontrada facilmente em boas bibliotecas e em diversos sebos de livros usados pelo país. O espetáculo foi produzido, teve sua dramaturgia adaptada e foi estrelado por Rosana Maris. A atriz afirmou ao site Artview que, por acreditar que corria o risco de mutilar uma obra de Williams e por a considerar impecável, quanto à estilística, a produção quis ser fiel ao máximo ao texto (Leão, 2011).

Esta versão traduzida por Viotti tem diversas ressalvas a serem discutidas, principalmente, considerando, por princípio, que toda tradução de dramaturgia 
sempre é datada e está impregnada de ideologias de seu momento histórico e do tradutor, já que "O teatro é um espaço de múltiplas traduções" (Buhunovsky, 2019, p.129). Exemplo disso é o título alterado, O anjo de pedra, usado a fim de tomar carona com a sua fama já disposta pelas montagens do TBC, embora não seja o mesmo texto fonte utilizado na tradução de R. Magalhães Jr.

Há apenas uma editora com a qual Williams tinha o compromisso em publicar suas obras, a New Directions, de Nova Iorque, cujo proprietário, James Laughlin, era seu amigo muito próximo. Assim, com essas publicações, o dramaturgo pensava em deixar suas obras para a posteridade. Ele tinha a nítida noção que serviriam para encenações futuras e como base de estudos para pesquisadores acadêmicos, por isso dispunha da fina preocupação em trabalhar incansavelmente em uma versão definitiva, aquela que estampasse o que de fato queria imprimir: sua poética, estilística e a matéria trabalhada.

Havia um cuidado primoroso, portanto, com as edições que seriam publicadas nessa editora, sendo que, muitas vezes, solicitou erratas, sempre negadas por Laughlin, querendo modificar ações, frases, palavras e até descrição de personagens, justificando que tinham sido escritas em um período em que estava possivelmente alterado por problemas pessoais. Esse perfeccionismo levou à publicação de obras ímpares da dramaturgia estadunidense.

Todavia, Williams não tinha a mesma preocupação com o texto que seria levado ao palco. Modificações, alterações e cortes sempre ocorreram, inclusive com variações muito relevantes. Para ele, tudo era resolvido no contrato. Assim que fosse assinado e efetuado o pagamento dos direitos autorais, a obra estava em mãos de profissionais capacitados. No caso de Summer..., encontrava-se nas mãos de sua grande amiga Margo Jones, e ele não iria se opor às suas adulterações. Porém, nesse caso, ele não gostou do que a diretora propôs, o que veio causar um rompimento da amizade. Ele considerou que as alterações no texto original foram tão drásticas que corrompeu sua peça, tendo como consequência o segundo fracasso de uma obra sua na Broadway. ${ }^{3}$ 
Duas importantes editoras de peças teatrais nos Estados Unidos focaram suas publicações em versões não oficiais, chamadas de edições para encenação [Acting editions]. A Samuel French, fundada ainda no Século XIX, com um grande número de obras teatrais publicadas e representante de seus direitos para encenação, e a Dramatists Plays Service [DPS], fundada em 1936, com os mesmos objetivos. As versões que foram levadas para os palcos em suas estreias, principalmente, são então o foco dessas editoras. Elas contêm reescritas de diálogos, os cortes dos diretores, inserções, variações em geral de planos de atuação, de iluminação e das marcações, além de até inserir contribuições dos atores.

Há, como referência, a famosa fala de Marlon Brando ${ }^{4}$ em relação a Kim Hunter na primeira montagem de Um bonde..., na Broadway, em que utiliza o termo fatty [gordinha, em tradução literal] quando sua personagem Stanley chama sua esposa Stella (Williams, 1981, p.58), replicada na versão da DPS.

Assim sendo, essa editora publicou todas as obras levadas à Broadway, além de algumas outras peças em um ato, nesse formato de acting edition. Portanto, não era a versão que Williams havia escolhido para que fosse publicada, não contém o que ele acreditava ser essencial para caracterizar sua estilística e sua matéria trabalhada.

Essas modificações não eram realizadas, em sua maioria, pelo autor, muitas delas foram anotadas por assistentes do diretor para que servissem de orientação para os atores e profissionais envolvidos na produção. No caso de uma substituição, o ator ou o técnico já saberia em detalhes como era a marcação, sendo preciso apenas estudar o que estava escrito. Essa prática revela uma preocupação com a dinâmica da montagem, evitando erros e problemas com permutas de profissionais. Todavia, dá um caráter produtivista

em reunião com o autor do artigo por meio da plataforma digital Zoom.

\footnotetext{
A frase se tornou famosa no contexto dos Estados Unidos. No Brasil, encenadores, pesquisadores, seguidores e os familiarizados com obras de Williams, em geral, não têm contato direto com os originais em inglês e desconhecem a existência e as discussões dos especialistas e encenadores estadunidenses sobre as diversas versões, mesmo em se tratando das obras mais celebradas e montadas. Acaba-se, portanto, muitas vezes, realizando uma encenação com a versão, com sua consequente tradução, que leve ao barateamento dos custos da produção, sabendo que não só os direitos autorais são altos para os padrões teatrais brasileiros, mas, também, a sua própria tradução.
} 
ao processo da encenação estadunidense, encarando o espetáculo como um produto manufaturado, que para ser atingida a versão final, deve ter as mesmas qualidades e características da produção e do desempenho dos atores e atrizes. A prática garantiria o rígido protocolo de sequência de tarefas que não poderia ser desobedecido.

Como um bom trabalho de ajudante de direção, a publicação traz ainda uma lista de objetos para auxiliar a contrarregragem e produção, além de uma planta baixa esquemática da cenografia, com proporções e medidas, além de uma relação de objetos de cena (Williams, 1998, p.80-82).

A versão utilizada por Viotti (Williams, 1998) é esta action edition da DPS. Há diferenças marcantes em relação à obra que Williams queria deixar para a posteridade, publicada pela New Directions (Williams, 1990). Essas diferenças serão discutidas nesse trabalho de forma geral e sem querer esgotar a argumentação, a fim de evidenciar que Summer... é, ainda, uma obra pouco conhecida no Brasil, não só pela ausência de encenações, mas pelo fato de que a única tradução disponível é a acting edition.

Infelizmente, não se sabe se foi o tradutor ou a editora brasileira que se absteve de publicar um esclarecimento sobre as duas versões e até a própria nota da DPS que explica essa acting edition. Aqui o trecho omitido da nota dessa edição brasileira:

Em outra versão desta peça há um curto prólogo que mostra John e Alma como crianças, brincando perto da fonte. Na versão atual, este prólogo foi omitido e certos aspectos dele estão inseridos em outra cena. No caso de algum grupo estar interessado em resgatar o prólogo, ele está incluído na edição para leitura que é publicada pela New Directions, e que pode ser encomendada pela sua livraria local. Se o prólogo for usado, há de se notar que certos aspectos dele, empregados em cenas posteriores na presente edição, não serão necessários. O prólogo foi omitido, principalmente, por causa da experiência na dificuldade, muitas vezes, em conseguir que crianças realizem trabalhos profissionais no teatro - Nota da editora (Williams, 1998, p. 4, destaque do autor). ${ }^{5}$

${ }^{5}$ In one version of this play there is a short prologue which shows John and Alma as young children playing by the fountain. In the present acting version this prologue has been omitted and some material from the prologue introduced into another scene. In case any group is interested in restoring the Prologue, this is included in the reading edition of the plays which is published by New Directions, and which may be 
O apontamento informa que, pela dificuldade de contratar atores mirins na década de 1940 no circuito da Broadway, houve a omissão do prólogo da peça, tendo seu conteúdo considerado mais importante - pelo autor da versão, talvez Margo Jones - realocado em outros momentos das ações ao longo da peça em forma de citação do passado pelas personagens de Alma e John, um recurso raso para resgatar a riqueza do conteúdo dessa cena. Além do prólogo, foi omitido o início da cena um.

O preâmbulo da peça era, de fato, difícil de ser levado para o palco na época por se tratar de um recorte do passado das duas personagens principais quando crianças: Alma e John Jr. A paixão de Alma já era revelada naquela época, assim como a atração de John pela garota, além de suas personalidades, segredos e, mais que isso, denota-se a dificuldade de Alma em lidar com a educação repressora diante de sua sexualidade, que transborda desde a puberdade.

Denota-se a crítica social de Williams já se revelando nessa cena inicial, que irá se interligar com as seguintes. A narrativa se desenvolve, portanto, crescente e exibindo as personagens aos poucos, construção aparentemente pueril com as crianças, mas que está intrinsicamente relacionada com o julgamento de Williams sobre a educação da mulher naquela sociedade repressora e sua formação religiosa, sendo ela criança ou adulta.

Um trecho do prólogo que foi omitido na versão traduzida por Viotti:

Ele agarra seus ombros e the dá um beijo rápido e áspero. Ela se espanta com uma mão segurando a outra. [...]. De repente, ele agarra a fita de cabelo dela, solta-a e foge com uma risada zombeteira. Ferida e perplexa, Alma volta-se para o anjo de pedra, em busca de conforto. Ela se agacha à sua frente e toca a inscrição com os dedos. A cena escurece com a música (Williams, 1990, p. 131). ${ }^{6}$

ordered through your local bookstore. If the Prologue is used it will be noted that certain material used in later scenes in the present edition will not be necessary. The Prologue was omitted primarily because of the difficulty often experienced in securing young children to act the parts - Publisher's Note. (Tradução nossa)

${ }^{6}$ He seizes her shoulders and gives her a quick rough kiss. She stands amazed with one hand cupping the other. [...]. He suddenly snatches at her hair-ribbon, jerks it loose and the runs off with a mocking laugh. Hurt and bewildered, Alma turns back to the stone angel, for comfort. She crouches at the pediment and touches the inscription with her fingers. The scene dims out with music. (Tradução nossa) 
O TBC não teve dificuldades para realizar a cena inicial da versão que apresentou em 1959. Contratou, os então adolescentes, Cláudio Cavalcante e Leny Vieira (TBC, 1959, p.15), seguramente, por aparentarem menos idade. Cláudio tinha 19 anos e Leny era a Narizinho do Sítio do picapau amarelo da TV Tupi, a primeira versão para a televisão. Todavia, essa acting edition, sendo um espelho da montagem de estreia na Broadway, revela a dificuldade daquele sistema em contratar jovens ou crianças para a realização de cenas tão controversas na década de 1940, como a apresentada por Williams na versão da New Directions, de conteúdo essencialmente psicológico e sexual - o casal infantil se beija na boca.

Nas notas da acting edition não há informações sobre essas diferenças em relação à versão da New Directions, também bastante significativas. Certamente, o tradutor sabia que essa não era aquela levada aos palcos pelo TBC. Não se sabe o que levou a editora e o tradutor a negligenciarem essa tão importante elucidação. Portanto, tal nota da editora omitida, se traduzida e publicada, seria uma referência para que os encenadores, pesquisadores, artistas e leitores em geral tivessem a nítida ideia de que era apenas uma versão de Summer...

Nessa obra de Viotti é possível encontrar um anacronismo léxico que dificulta a fluência do texto se lido na contemporaneidade, necessitando de uma reescrita para se adaptar à linguística atual. Chama-se a atenção, como exemplo, de algumas expressões, tais como: "felicidade conubial" (Williams, 1968b, p.120), no original "connubial felicity" (Williams, 1998, p. 50), que estaria mais próxima do público atual se fosse traduzida, por exemplo, como felicidade conjugal; “aparência plácida” (Williams, 1968b, p. 200), no original "surface” (Williams, 1998, p.49), que seria somente aparência. Como as expressões são apresentadas, podem causar estranhamento ao público brasileiro contemporâneo, avesso a palavras pouco corriqueiras ou rebuscadas, como conubial e plácida. Acrescentar adjetivos que não estão no original é praxe deste tradutor ao longo da peça, o que ocorre em diversas outras instâncias. Portanto, o que seria necessário ao se considerar essa versão para os palcos é uma tradução intralingual, que implicaria na reformulação de signos verbais, concordando com as discussões sobre 
tradução de textos teatrais trazidas pela pesquisadora Ruth Bohunovsky (2019, p.131).

Nas "Notas de produção do autor" (Williams, 1998, p.4-5)7 do texto fonte, Williams descreve os detalhes da peça, também presente na versão da New Directions (Williams, 1990, p.119-121). Nela o autor explica como deve ser o céu com uma clareza literária e artística que leva a peça quase a um conto: o céu do dia é tão azul quanto aqueles retratados nas pinturas renascentistas, já o da noite deve conter a projeção de diversas estrelas e até constelações. Uma clara alusão ao céu de Roma, onde o texto fora escrito durante um plácido verão.

Com relação aos cenários da casa episcopal e do consultório médico, Williams chega às particularidades da arquitetura gótica, lembrando a era vitoriana, além de fazer comparações com o quadro Conversação entre as ruinas [1927] do pintor italiano Giorgio De Chirico, dado o nível estético que ele espera sobre a compreensão de sua peça, assim como da cidade vista do local onde está o chafariz - outra referência italiana. Há também uma descrição pormenorizada do parque que contém a fonte, seus detalhes e os da estátua do anjo sobre ela, indicando o quanto esse espaço do cenário deve ser mais importante que os interiores das casas. Na versão da New Directions, Williams inseriu, ao final das notas, recomendações quanto à trilha sonora, que não está na acting edition (Williams, 1990, p.121).

As rubricas da cópia traduzida são verdadeiras reformulações que se distanciam das características essenciais da estilística tennessiana, principalmente no que diz respeito ao seu lirismo. Foram deixadas de lado a ambientação das cenas com descrições psicossociais, referências estéticoculturais e sua grande preocupação com a caracterização das personagens, tal como fez na descrição do cenário. Nessa versão, o que existe é uma delimitação de posicionamentos de atores, gestos e objetos de cena que dificulta, por exemplo, uma simples leitura do texto. "Winemiller: Então vamos andando, 'mamãe'. [Ele dá a bolsa a Alma e vai saindo pela D.A. A senhora Winemiller começou a vaguear pela E.A. Ele cruza até ela] Por aqui, 'mamãe', por aqui. 
[Pega-a pelo braço e vai levando-a pela D.] (Williams, 1968b, p.23, destaques do autor). D.A., E.A. e D. seriam, respectivamente, abreviaturas de direita alta, esquerda alta e direita, terminologia tradicional para marcações de deslocamento no palco.

Ao se comparar com a acting edition da editora Samuel French da peça You Touched Me! (Williams; Windham, 2010), o mesmo não acontece com as rubricas, lembrando que era a mesma diretora. Não se sabe se isso aconteceu porque houve uma participação maior do autor quando da encenação ou por causa da presença do coautor Donald Windham, mas está claro que o processo de encenação, em 1945, era outro. Mesmo porque essa obra nunca foi publicada pela New Directions, o que revela um desinteresse do autor em deixá-la para a posteridade.

No final da cena quatro, a versão para o palco retira duas falas das personagens Mrs. Bassett e Roger, sendo que a dela é acrescentada na fala anterior - uma desconstrução de diálogo repetida em vários outros momentos do texto. Assim sendo, há, também, a evidência de rudimentos do que é chamado dramaturgismo nos dias atuais, uma modificação/adaptação do texto fonte para o palco, desde que a versão venha a desempenhar o papel de uma espécie de guardiã do sentido ou até mesmo guardiã da sala de ensaio. Na rubrica final dessa mesma cena é citada uma valorização da estátua do anjo, o que não existe no texto original da New Directions. E, por fim, a nota acrescentada pelo tradutor, mostra sua preocupação, da mesma forma, com a logística da marcação das cenas. Notas como essa também ocorrem fartamente em outras cenas posteriores. A reprodução desse trecho nas duas versões é apresentada:

Roger: [Levantando-se] Proponho que se encerre a reunião.

[Vernon se levanta, vai colocar a sua cadeira no lugar, na D. A. e sai pela D.]

Sra. Bassett: [Saindo pela D.] Eu apoio a moção. Coitada da Srta. Alma! Rosemary: [Lentamente, sem entender direito, enquanto sai pela D.] Não estou compreendendo nada; Que foi que aconteceu?

[As luzes escurecem completamente na casa dos Winemillers.] As luzes no anjo e no céu aumentam um pouco.

Nota: Os atores que tomarem parte nesta cena devem levar consigo os 
objetos de cena, leques, etc., ao sair (Williams, 1968b, p.88).

Roger: Proponho encerrarmos a reunião.

Sra. Bassett: Apoio a proposta.

Rosemary: Não entendi. O que aconteceu?

Sra. Bassett: Pobre senhorita Alma!

Roger: Ela não tem sido ela mesma ultimamente...

[Todos eles saem. Depois de um momento, Alma volta e entra com uma bandeja de refrescos, olha para o ambiente vazio e cai na gargalhada histérica. As luzes se apagam.] (Williams, 1990, p. 177). ${ }^{8}$

Nesse recorte, a rubrica da versão da New Directions tem uma função bastante específica e diversa da action edition, que seria a de revelar uma particularidade psicológica da personagem Alma, como sugere a tradução proposta: sua histeria. Na versão da DPS, a caracterização da personagem como uma mulher alterada nessa cena não faz parte do entendimento dramatúrgico para a construção da cena e da personagem principal. Ela serve apenas para marcar posições de atores no palco.

No final da cena cinco da versão para o palco, mais uma vez se desvia a atenção para a estátua do anjo, iluminando-o, expediente bastante usado nessa variante. Na publicada pela New Directions, nessa cena, Williams ilumina o mapa de anatomia na sala do médico. A estátua não é um elemento importante nesse momento da dramaturgia, dado que a matéria trabalhada é sobre as convicções religiosas e conservadoras de Alma, tendo John pedido para que ela localizasse a alma naquele mapa. Uma metáfora importante sobre as questões que envolvem a visão crítica do autor sobre a educação religiosa feminina.

O foco no mapa de anatomia permitiria uma abordagem que remeteria aos cartazes do teatro épico que informam mais do que o dialogismo, viabilizando uma reflexão do público acerca das questões críticas sobre as crenças religiosas em contraposição com a ciência. Elemento dramatúrgico bastante pertinente, portanto, para a compreensão daquilo que o dramaturgo tinha, de fato, como

${ }^{8}$ Roger: I move that the meeting adjourn.

Mrs. Bassett: I second the motion.

Rosemary: I don't understand. What happened?

Mrs. Bassett: Poor Miss Alma!

Roger: She hasn't been herself lately...

[They all go out. After a moment Alma reenters with a tray of refreshments, looks about the deserted interior and bursts into hysterical laughter. The lights dims out.]. (Tradução nossa) 
matéria trabalhada: a crítica social e religiosa. Tal como fez em Not about Nightingales [Não será sobre rouxinóis, 1938], ao retratar o capelão de um presídio de forma paródica e corrupta.

Quanto à iluminação sobre a estátua do anjo na transição de uma cena para outra, que não existe na obra para leitura, Viotti insere a seguinte orientação: um "efeito especial sobre o anjo" (Williams, 1968b, p.108). A contemplação da imagem da estátua justifica o título escolhido para a peça, solidificando-o. Esse se revela um efeito psicologizante sobre a leitura do original, potencializando a ideia de luta entre a angelitude e a pureza da personagem Alma, com as características terrenas de John, seu opositor. Assim, intensifica-se o caráter maniqueísta, da eterna luta da carne e do espírito, personificando o mal e o bem, respectivamente.

Revela-se, então, uma leitura conservadora e puritana sobre questões morais que envolvem a sexualidade, ou a carne. Leva o texto para ser lido apenas pelo viés melodramático e privado, afastando a possibilidade de reflexões críticas acerca da sociedade religiosa/conservadora que modula a educação feminina com submissão, supressão da sexualidade e impedimentos em relação à sua subjetividade. De fato, Williams considerou a versão de Margo Jones excessivamente melodramática (Maruéjoulis-Koch, 2014, p.20).

Sob este aspecto, pode-se compreender que os embates de Alma com John são levados para o campo das emoções e das sensações, abrindo caminhos para a interpretação exclusivamente psicológica. Cenas mais calmas e eloquentes são intercaladas com os enfrentamentos sentimentais do casal de forma movimentada ou, até mesmo, patética. Talvez, seja por esse motivo que há dificuldades da leitura reflexiva acerca das questões críticas sobre a religião e a sociedade. Pois, a ação romanesca é colocada como superlativa e espetacular, revelando um melodrama que não apresenta um reflexo social, mas a ilusão teatral e sua fascinação.

Há dois momentos, apenas, em que Tennessee sugere que haja a iluminação na estátua. O primeiro é na transição da parte um para a parte dois, 
que Viotti traz como ato um e ato dois. A acting edition retira essa iluminação, tendo-a colocado em todas as outras mudanças das sete cenas anteriores. Com isso, pode-se entender que a iluminação é um destaque metafórico do autor sobre a insistência de Alma em não aceitar as investidas de John, dizendo que ele não seria um cavalheiro, por fazer propostas indecentes, além da transição do verão para o inverno na segunda parte. Ela se revela angelical, pudica, sacrossanta. "John: [...] Você estaria segura tal como o anjo da fonte - porque eu não me sentiria decente o suficiente para tocar em você..." (Williams, 1990, p.222). ${ }^{9}$

A estátua de pedra seria, portanto, uma representação de uma pureza endurecida, intolerante, sem movimento, que não possibilita progressão e acolhida, ocorrendo novamente na segunda parte, na transição da cena sete para a cena oito. Aqui há o assassinato do doutor Buchanan por Gonzales. A iluminação na estátua do anjo é sugerida apenas nas asas, na versão da New Directions. Tal versão mostra, desse modo, uma desfiguração imagética da simbologia da religiosidade, da inocência e da paz na idílica cidade sulista que cultiva as aparências de moralidade. A versão para o palco coloca, em seu lugar, apenas mais uma nota para indicar movimentação de atores, ignorando a poética do autor para a constituição da dramaticidade e entendimento da matéria trabalhada.

Ressalva-se que a cena dois da primeira parte não está no original da New Directions. Porém, faz parte da versão traduzida no Brasil. Nela, Alma está em consulta com o doutor Buchanan, pai, e confessa sua virgindade, além de suas ansiedades. A conversa de cunho sexual é bastante explícita, fora do padrão estilístico de Tennessee, que deixava apenas pistas sobre essas questões. Jamais usando os termos sexuais de forma tão determinada e direta naquela época. A ambiguidade e a ambivalência sempre foram seus maiores trunfos estilísticos, mormente em relação ao desejo, sua figuração e o sexo em geral.

9 [...]. You'd have been as safe as the angel of the fountain - because I wouldn't feel decent enough to touch you... (Tradução nossa) 
Doutor: Só tenho isto para dizer, Alma [Com um gesto, pede-lhe que se sente, o que ela faz.] Você precisa saber se o lado sexual do casamento significa alguma coisa para você ou não. Muitas mulheres preferem um fulano bem-educado, que não beba, que seja fácil de levar. Por outro lado, há mulheres que querem amor e querem ser amadas com paixão física. [Alma vira o rosto, lenta e gravemente.] A que grupo você pertence senhorita Alma?

Alma: Creio na possibilidade de um amor profundo entre um homem e uma mulher.

Doutor: Ótimo! Amor físico? [...]. Você nunca foi tocada por outra pessoa? [Alma vira o rosto.] Quer dizer, alguém já lhe tocou a mão sem provocar esta sensação desagradável?

Alma: Já. Não sou uma pessoa fria (Williams, 1968b, p.58-59).

O médico discute com ela sobre a importância da vida sexual e pergunta se seria o tipo de mulher que sente desejo, ela diz que não é. Ainda explicita o tom íntimo, perguntando se já foi tocada. Há uma supervalorização de expedientes que Williams apenas deixava nas entrelinhas, como fruto de seu lirismo. Um forte indício de que o autor pode não ter escrito a cena completamente, tendo apenas esboçado um rascunho para a diretora. Também há uma conversa sobre John, o filho, que chega depois de uma noite boêmia, sendo expulso pelo pai e logo depois reconsiderado. A cena três dessa versão seria, então, a de número dois do texto da New Directions.

Quando a peça foi encenada pelo TBC, Tennessee tinha sido pouco encenado e estudado no Brasil. Dessa forma, escassas referências eram encontradas sobre o autor. Tido como um dos grandes dramaturgos estadunidenses daquele momento, a obra de Williams era um instrumento potencial para a modernização do teatro brasileiro, que, até então, estava muito voltado para obras do início do século ou de autores consagrados europeus de séculos passados, como Shakespeare, Molière e o teatro português. A dramaturgia estadunidense surgiu, assim, como um elemento extravasador para um teatro que carecia de novas propostas estéticas para se expandir e formar público.

No Rio de Janeiro, peças de Nelson Rodrigues sob a direção de Ziembinski, como Vestido de noiva [1943], já levaram inovações tão pronunciadas que foram responsáveis por notórias e históricas conquistas para a modernidade cênica no 
país. O TBC investiu, assim, muito na dramaturgia estadunidense, além de outras europeias, como aporte assertivo do progresso e da renovação do teatro moderno paulistano. Além disso, inovou ao apostar em novos dramaturgos brasileiros tais como Jorge Andrade e Abílio Pereira de Almeida.

No momento histórico em que a tradução foi publicada, no entanto, já havia uma leitura da obra de Williams por Augusto Boal, que a trouxe consigo de sua estadia de três anos nos Estados Unidos. O teatrólogo a expôs nos seminários do Teatro de Arena, realizados a partir de 1958, quando começou a indicar o dramaturgo e sua peça Um bonde... como modelo dramatúrgico para se obter uma peça bem escrita (Betti, 2015, p.164). Boal apresentava todo o conjunto de peças conhecidas de Williams até então - talvez meia dúzia delas - como de realismo psicológico, autobiográfica e de representação estereotipada do Sul dos Estados Unidos, tal como no filme E o vento levou, exclusiva e excludentemente. Essa leitura foi apreendida no país, sem discussão ou crítica, e perdura até os dias atuais, mesmo sabendo que o autor tem mais de 150 peças escritas, muitas delas em formatos experimentais.

\section{O verão e a fumaça}

Embora depositadas nos arquivos de bibliotecas estadunidenses, há muitas versões deste texto, cada uma delas com títulos muito diferentes. O dramaturgo sempre refletia muito sobre a nomeação de suas obras. Thomas Keith (2018, p.169-170) cita as outras denominações das diversas versões: The Chart of Anatomy [O mapa de anatomia], The Bird Girl in His Arms [A moça passarinho em seus braços], Fiddler's Green [O gramado do violinista], The Good Time House [A casa dos bons tempos], The Room is Cold [A sala está fria], Scenes of a Magic Lantern [Cenas de uma lanterna mágica], Portrait With a Parasol [Retrato com um guarda-sol] e World of Light and Shadow [O mundo de luz e sombra]. Todas bem diferentes uma da outra, mas nenhuma faz menção à estátua do anjo de pedra, uma possibilidade aparentemente improvável para o autor. 
A alteração do título da peça no Brasil traz uma discussão a ser ressaltada. Como a tradução pode ter sido um trabalho resultante de debates com produtor, atores e, principalmente, o[s] diretor[es], é bem provável que a figura emblemática, fácil e gritante da estátua do anjo tenha chamado mais atenção do TBC que o poético, profundo e enigmático título original. Este, claramente, uma referência mais expressionista e o outro muito mais realista e melodramático devido a sua redundância e obviedade nas cenas. Tendo o realismo psicológico como carro chefe da leitura hegemônica, ele foi preterido ao título original.

Na década de 1950, a atriz francesa que vivia no Brasil, Henriette Morineau, ao fazer a primeira montagem de Um bonde... preferiu o confuso e disperso título, embora comercial, Uma rua chamada pecado, que depois foi reproduzido para a versão fílmica. Décio de Almeida Prado informa este fato: "Foi ela [Mme. Morineau], por exemplo, quem nos deu a conhecer o teatro americano de pósguerra, encenando A Street Named Desire, de Tennessee Williams, sob o título, julgado mais provocante, de Uma rua chamada pecado" (Prado, 2009, p.42). O prestigiado pesquisador, professor da Universidade de São Paulo e crítico teatral, escreve até o nome da peça errado, trocando Streetcar por Street, a fim de validar o título reiterado por Mme. Morineau: a tradução de streetcar é bonde e a de street é rua. Rememorando também o disperso título À margem da vida para The Glass..., certificado por Esther Mesquita, a tradutora da primeira versão da peça encenada no Brasil em 1948.

Apaixonado pelo poeta modernista estadunidense Hart Crane, desde que o descobriu em 1934, Williams utilizou também seus poemas como inspiração de peças, citando frases nas falas das personagens e epígrafes em diversas obras, como em Um bonde... e Doce pássaro da juventude [Sweet Bird of Youth, 1956]. Crane foi, também, personagem em Steps Must Be Gentle [Os passos devem ser leves, publicada em 1980]. A peça aqui cotejada teve seu título retirado de um poema de Crane de 1927, Emblems of Conduct [Emblemas de conduta], uma reescrita do poema Conduct [Conduta] do poeta austríaco-americano Samuel Greenberg, mas considerado um trabalho original, dada a sua profundidade lírica. O trecho do poema, com uma arriscada tradução literal, apenas para 
compreender a conjuntura de onde a frase foi retirada, é o seguinte:

O viajante depois escolheu este local de descanso

Onde nuvens de mármore sustentam o mar

Para onde finalmente foi levado um herói escolhido.

Naquela época, o verão e a fumaça já haviam passado.

Golfinhos ainda brincavam, arqueando nos horizontes,

Mas apenas para construir memórias de portões espirituais

(Crane, 2020, destaque nosso). ${ }^{10}$

A expressão Summer and Smoke, aqui com a proposta de tradução O verão e a fumaça, retirada da tradução da frase do poema, é intrigante e não possui o mesmo atrativo comercial da expressão O anjo de pedra, como visto. Há diversas aproximações que se podem investigar para justificá-la como o título definitivo. A primeira é aquela que perquire a tênue ligação, quase espiritual, entre as personagens principais, tal como sugestiona a remissão do poema de Crane, já que a figura remete à tradição religiosa que o define como um ser puramente incorpóreo.

John: Eu estou pensando da sua maneira, que algo mais existe lá, algo imaterial - fino como a fumaça - que todas essas máquinas horríveis se combinem para produzir e essa é a razão de ser delas. Não pode ser visto, portanto não pode ser mostrado no mapa. Mas está lá, do mesmo jeito, e sabendo que está lá - por que, então, a coisa toda - essa - essa nossa experiência insondável - assume um novo valor, como um - um experimento romântico e descontrolado de laboratório! Você não vê? $[\ldots]$

Alma: Entendo! Agora que você não quer que seja diferente, está disposto a acreditar que um vínculo espiritual pode existir entre nós dois! (Williams, 1990, p. 244).11

Na tradução de Viotti, a palavra fumaça é substituída por "fumo" (Williams,

\footnotetext{
10 The wanderer later mode chose this spot of rest

Where marble clouds support the sea

And where was finally borne a chosen hero.

By that time summer and smoke were past.

Dolphins still played, arching the horizons,

But only to build memories of spiritual gates. (Tradução nossa)
}

11 John: I've come around to you way of thinking, that something else is in there, an immaterial something as thin as smoke - which all of those ugly machines combine to produce and that's their whole reason for being. It can't be seen so it can't be shown on the chart. But it's there, just the same, and knowing it's there - why, then the whole thing - this - this unfathomable experience of ours - takes on a new value, like some - some wildy romantic work in a laboratory! Don't you see? [...]

Alma: Yes, I see! Now that you no longer want it to be otherwise you're willing to belive that a spiritual bond can exist between us two! (Tradução nossa) 
1968b, p. 170), o equivalente em espanhol ou em português de Portugal, uma maneira de minimizar o termo original, fumaça, para salientar a escolha divergente de título, porém dificultando, ou embaralhando, a compreensão do texto. Está aqui nessa citação uma das razões do título original, visto a fumaça ser comparada à essência humana por John. Por essa razão, há um elemento expressionista pouco percebido nessa obra por conta do título trocado.

Em outro trecho, há menção à fumaça e que traz uma interpretação expressionista sobre o título:

Alma: [...] Pensei muitas vezes em algo que você me disse no verão passado, que tenho um Doppelgänger. Pesquisei e descobri que significa outra pessoa dentro de mim, outro eu, e não sei se devo agradecer ou não por me conscientizar disso! - Não estive bem... Por um tempo pensei que estava morrendo, que era a mudança que estava por vir.

John: Quando você teve esse sentimento?

Alma: Agosto. Setembro. Mas agora o vento do mar levou esse sentimento como se fosse uma nuvem de fumaça, e eu sei agora que não estou morrendo, que não será tão simples assim... (Williams, 1990, p. 241). ${ }^{12}$

A sensibilidade de Alma sobre uma possível de mudança pessoal the causava a intuição de morte, como se sua vida ficasse embaçada por uma fumaça, fato que acontecia no verão, estação das paixões avassaladoras. Não se devem esquecer as neblinas dessa estação também como um dado climático referente ao Rio Mississipi durante as cheias, pois a serração invade a cidade e causa dificuldade de visão.

O Doppelgänger é o mito das culturas nórdica e germânica, portanto tradicional na Alemanha, que dispõe sobre um suposto duplo do indivíduo, geralmente associado com o seu lado sombrio ou maligno. O autor já preparava o final da peça com essa remissão acertada sobre essa mitologia, uma metáfora que cresce na última cena, quando Alma supera a educação religiosa e opressora

${ }^{12}$ Alma: [...]. I've thought many times of something you told me last summer, that I have a Doppelgänger. I looked that up and found that it means another person inside me, another self, and I don 't know whether to thank you or not for making me conscious of it! - I haven't been well... For a while I thought I was dying, that was the change that was coming. John: When did you have that feeling? Alma: August. September. But now the Gulf wind has blown that feeling away like a cloud of smoke, and I know now I'm not dying, that it isn't going to turn out to be that simple... (Tradução nossa) 
e, finalmente, se transforma em outra mulher.

A tradução portuguesa tem, por sua vez, um título muito mais próximo da ideia de Williams ao caracterizar Alma: Fumo de verão (Williams, 1964a). Foi realizada com base na versão da New Directions, feita por Luis de Sttau Monteiro e publicada pela primeira vez em 1962, em Portugal. Segundo o dicionário Infopédia (Fumo..., 2020), o verbete fumo, entre os muitos significados, é fumaça e, também, pode ser definido neste contexto por: "vapor que se desprende de corpos húmidos ${ }^{13}$ ou de líquidos quando mais quentes que o ambiente onde se encontram". Seria, portanto, uma nuvem que embaça a visão, uma neblina, um nevoeiro, cerração ou, até mesmo, uma escuridão.

Assim, o título poderia ser transposto, acertadamente, para Fumaça de verão, Neblina de verão ou $A$ escuridão do verão, pelo fato de expressarem melhor a poética expressionista. Sendo que em todas as expressões, semanticamente, procura-se a significação do impedimento da visão, da percepção do que acontece no outro e em si mesmo. O título, portanto, estaria umbilicalmente ligado à personagem Alma e à educação repressora, que the causa um comportamento desajustado e excêntrico, impedindo-a de viver sua subjetividade plena e seu amor por John. O título português revela que o tradutor possivelmente entendeu a proposta expressionista do dramaturgo e a expressão utilizada no título.

\section{As excentricidades de um rouxinol: outra versão, outra peça}

Para uma encenação em Londres, em 1951, Tennessee preparou uma versão bastante diferente da original publicada pela New Directions, com o título The Eccentricities of a Nightingale. Todavia, quando a apresentou, os ensaios com a outra versão já estavam adiantados e não houve tempo para a troca de texto. Só teria sua primeira encenação somente em 1964, no entanto, sendo levada à Broadway em 1976, com direção de Edwin Sherin. As montagens foram, também, fracassos de público e crítica na carreira do dramaturgo.

\footnotetext{
${ }^{13}$ Escrita conforme o dicionário português.
} 
No Brasil, The Eccentricities... foi negligenciada, talvez pelo interesse assoberbado em peças de sucesso comercial no circuito da Broadway e pela ausência de tradução. Além disso, há o fato de Summer... não ser uma peça popular no país, com escassas montagens. Observa-se uma confiança exclusiva na crítica estadunidense, e também na brasileira, que afirmam serem as obras primas de Williams apenas aquelas encenadas e celebradas pelo mainstream.

The Eccentricities... possui diferenças salientes com o texto da New Directions, que são assinaladas abaixo:

a) Eliminou algumas personagens: Dr. John Buchanan, pai; Nellie Ewell, a aluna de canto de Alma que se torna noiva de John, filho, no final; e a família Gozales, Rosa e seu pai;

b) Acrescentou uma nova personagem: a mãe de John. A matrona tem uma paridade com outras mães autoritárias, que dá a impressão que Williams estava apenas reproduzindo as figurações maternas já trabalhadas anteriormente: senhora Critchfield, mãe de Heavenly, de Spring Storm [Tempestade de primavera, 1937]; senhora Fenway, mãe de Donald em Summer at the Lake [Verão no lago, 1937]; e a mais famosa das mães da dramaturgia estadunidense, Amanda Wingfield, de O zoológico de vidro;

c) Como não há mais a família Gozales que assassina John, pai, não há mais morte na peça, não há tiro ou cenas de violência, que antes funcionavam em summer... como um contraponto às partes melodramáticas dos embates de Alma e John;

d) Sem a família mexicana, o Casino Moon Lake também foi excluído;

e) A cena mais carnal, portanto, acontece no quarto de um hotel barato;

f) Alma e John fazem sexo neste quarto, finalmente; 
g) John não é mais um homem do mundo, como em Summer..., é menos tempestuoso, menos amoral e é controlado pela mãe;

h) A característica principal de Alma, que nomeia a peça, é a afetação bem mais pronunciada, uma moça excêntrica, que deixa mais evidente as consequências da educação religiosa controladora e castradora mediante um comportamento histriônico. Ela é uma mulher mais mundana e suas ambiguidades ficam mais evidentes, porquanto torna a personagem mais humana;

i) Algumas cenas foram retiradas completamente, substituídas por outras. Algumas foram reescritas, com diálogos inteiros ratificados, incluindo a cena final, um pouco mais objetiva e curta. Agora, ela fala sobre a estátua do anjo, descreve-a em detalhes, o que em Summer... não há. Na peça original, o rapaz a convida para ir ao casino, mas na nova versão ela o convida para ir à Tiger Town, uma região da cidade com bares, casas de jogos e hotéis baratos, o que ele aceita prontamente. Summer... termina com o caixeiro viajante pedindo um táxi, na nova versão eles vão caminhando até casualmente encontrar um, ele na frente e ela atrás dele ao som da Valsa Santiago e iluminação sobre a estátua do anjo. A mesma valsa seria sugerida por Williams na peça The Mutilated [As mutiladas, 1964], 15 anos depois. Historicamente, este estilo musical sempre foi tido como pecaminoso, depois se tornando clássico e apreciado pela aristocracia. Assim, a alegre valsa faz um contraponto com Alma, uma mulher que sofre uma transformação tal como a reputação da valsa na sociedade, utilizando de uma laconicidade lancinante, porém poética. Assim, afasta o tom melodramático que estampa o final da outra versão.

No entanto, as personagens centrais ainda estão lá: Alma, professora de música, e John, estudante de medicina, vivendo na mesma cidade sulista, alguns anos antes da Primeira Guerra. Alma continua a mesma moça frustrada pela educação religiosa, filha do ministro anglicano e ainda tem a mãe com 
desequilíbrio mental. Mais enxuta e mais direta, essa versão era preterida pelo autor.

\section{Tennessee Williams - esse desconhecido!}

William não queria falar da dignidade do homem e da mulher em Summer and Smoke, mas de suas ambiguidades. Com uma leitura pouco aprofundada e descontextualizada, a peça pode ser entendida como uma fábula, um melodrama que quer evidenciar a luta do espírito e do corpo. Porém, ao se revelar as circunstâncias sociológicas, culturais e históricas, percebe-se um autor profundamente consciente e crítico da condição da mulher na sociedade misógina e teocrata, que determina seu papel social em face da moral religiosa.

Com um julgamento sobre a educação conservadora, Williams evidencia uma mulher em conflito com suas ambivalências e indeterminações em relação a ela mesma, ao ter que se relacionar com o sexo oposto, expressar suas subjetividades e a sexualidade.

O fato de a tradução de Summer..., disponível no Brasil desde o ano de 1964, ser de uma versão diferente daquela que o autor intencionava ver publicada, reflete um desconhecimento por parte dos brasileiros da biografia do autor e sua obra. A versão brasileira avigora aspectos da fábula melodramática sobre a relação improvável de Alma e John, firmando pouco espaço para leituras críticas acerca da sociedade, da religião e do machismo.

Alma é uma personagem que sofre com a repressão imposta às pulsões sexuais, deslocando-a do protocolo imposto como felicidade para uma mulher na sociedade - ela é vista, portanto como inadequada aos padrões concorrenciais da sociedade capitalista. Os diálogos de Summer... tendem ao lírico, apresentando uma narrativa que remete à memória, seja de identificação biográfica ou do imaginário. E estes são reconhecidamente mecanismos que também reconfigurariam a modernização dramatúrgica do teatro brasileiro, daí a importância da peça no Brasil.

O público, os artistas, os pesquisadores, os seguidores e os admiradores 
que não têm contato com o texto original da New Directions, ainda não conhecem o lirismo de suas rubricas, o uso de expedientes expressionistas e desconsideram a consciência sociológica de um autor que é lido tradicionalmente como realista e psicológico. Dessa maneira, não conseguem ainda entender que esta obra figura o julgamento de Williams sobre a sociedade sulista dos Estados Unidos com seus preceitos moralistas que destroem subjetividades e a vida privada da mulher.

\section{Referências}

ALVES, Jr., Dirceu. O anjo de pedra vai para o palco com sensibilidade. In: Veja São Paulo. 1/07/2011. Disponível em: <https://vejasp.abril.com.br/cidades/o-anjode-pedra-montagem-delicada/>. Acesso em: 27 Jun. 2020.

BETTI, Maria Sílvia. O impulso e o salto: Boal em Nova York (1953-1955). In: Sala Preta, v01. 5, p.156-179, 2015. Disponível em:

<http://www.revistas.usp.br/salapreta/article/view/97308/98325>. Acesso: 9 Abr. 2020.

BILLINGTON, Michael. Summer and Smoke Review - Gripping Return for Rare Tennessee Williams. In: The Guardian. 8 mar. 2018. Disponível em: <https://www.theguardian.com/stage/2018/mar/08/summer-and-smoke-reviewtennessee-williams-patsy-ferran-almeida>. Acesso: 22 set. 2020.

BOHUNOVSKY, Ruth. Traduções no teatro, feitas para publicar, encenar ou legendar: uma tipologia possível. In: Urdimento, Florianópolis, v. 2, n. 35, p. 129148, ago./set. 2019. Disponível em:

<http://www.revistas.udesc.br/index.php/urdimento/issue/view/638>. Acesso: 4 Jul. 2020.

CRANE, Hart. Emblems of Conduct. Disponível em: <https://genius.com/>. Acesso: 30 Jun. 2020.

FUMO. In: Infopédia - Dicionários Porto Editora. Disponível em: <https://www.infopedia.pt/dicionarios/lingua-portuguesa/fumo>. Acesso: 2 Jul. 2020.

KEITH, Thomas. Tennessee Williams: Experimentation and the 'Great American Play'. In: LONDRÉ, Felicia Hardson (Ed.). Modern American Drama: Playwriting in the 1940s - Voices, Documents, New Interpretations. New York: Bloomsburry Publishing, 2018. p.151-175. 
LAWRENCE, David Herbert. A virgem e o cigano. Alexandre Pinheiro Torres (Trad.). São Paulo: Círculo do livro, 1970. 155 p.

LAWRENCE, David Herbert. The Virgin and the Gypsy. Disponivel em: <https://freeditorial.com/en/books/the-virgin-and-the-gipsy/related-books>. Acesso: 29 Jun. 2020.

LEÃO, Luiz Henrique. O Anjo de pedra volta em cartaz agora no Teatro Coletivo no ano do centenário de Tennessee Williams. In: Arte view, 11/ago./2011. Disponível em: <https://arteview.com.br/o-anjo-de-pedra-volta-em-cartazagora-no-teatro-coletivo-no-ano-do-centenario-de-tennessee-williams/>. Acesso: 22 jul. 2020.

MARUÉJOULIS-KOCH, Sophie. The Haunted Stage of Summer and Smoke: Tennessee Williams's Forgotten Silent Film Sequences. In: Modern Drama, Vol. 57, No 1, Spring, 2014, p.19-40. Disponível em: <https://muse.jhu.edu/article/541009>. Acesso em: 4 Jul. 2020.

PALMER, R. Barton; BRASY, William Robert. Hollywood's Tennessee - The Williams Films and Postwar America. Austin: University of Texas Press, 2009.

PRADO, Décio de Almeida. O teatro brasileiro moderno. São Paulo: Perspectiva, 2009.

TEATRO BRASILEIRO DE COMÉDIA (TBC). O anjo de pedra - programa da peça. São Paulo/Rio de Janeiro, 1959.

WILLIAMS, Tennessee. 49 contos de Tennessee Williams. Alexandre Hubner et al. (Trad.). São Paulo: Companhia das letras, 2006.

WILLIAMS, Tennessee. A Streetcar Named Desire - A Play in Three Acts - Acting Edition. New York: Dramatists Play Service, 1981.

WILLIAMS, Tennessee. A Streetcar Named Desire - Students Edition. London: Methuen Drama, 2009.

WILLIAMS, Tennessee. Collected Stories. New York: New Directions, 1994.

WILLIAMS. Tennessee. Fumo de verão. Luis de Sttau Monteiro (Trad.). Lisboa: Publicações Europa-América, 1964a.

WILLIAMS, Tennessee. O anjo de pedra. Sérgio Viotti (Trad.). Rio de Janeiro: Bloch Editores, 1968b.

WILLIAMS, Tennessee. Summer and Smoke - Acting Editing. New York: Dramatists Plays Service, 1998. 
WILLIAMS, Tennessee. The Theatre of Tennessee Williams - Vol. 2. New York: New Directions, 1990.

WILLIAMS, Tennessee; WINDHAM, Donald. You Touched Me! A Romantic Comedy in Three Acts. New York: Samuel French, 2010.

Recebido em: 18/10/2020

Aprovado em: 07/02/2021 